\title{
Uma nova introdução a Michel Foucault
}

\author{
Rafael Faraco Benthien \\ Universidade de São Paulo \\ São Paulo, SP, Brasil \\ rfbenthien@hotmail.com
}

BERT, Jean-François. Introduction à Michel Foucault. Paris: La Découverte, 2011, 125 p.

O livro Introduction à Michel Foucault vem a público pela editora La Découverte, a qual integrou-o em sua coleção Repères: Sociologie. Devido a seu formato e tamanho, pouco mais de 120 páginas entrecortadas de blocos de texto e de glossários, ele não almeja nem apresentar interpretaçóes revolucionárias do pensamento do filósofo francês, nem levar adiante um ou outro de seus resultados e métodos. Trata-se, basicamente, de uma obra de divulgação voltada a estudantes universitários. Ainda assim, em meio a tantos manuais que se comprazem em repetir o mesmo, esse tem o mérito de estimular o pensamento do leitor. Afinal, evitando as simplificaçóes e a idolatria que tendem a caracterizar esse gênero tipicamente escolar, quer-se promover aqui uma reflexão com e contra Foucault.

A escolha do autor não poderia ser, quanto a isso, mais feliz. Jean-François Bert tem com a produção foucaultiana uma intimidade atípica, a qual vem se constituindo desde 2002, quando teve início seu doutorado dedicado à recepção de Foucault nas ciências sociais francesas ${ }^{1}$. Nesse contexto, em paralelo ao estudo de obras impressas, Bert se voltou à exploração sistemática dos arquivos pessoais e profissionais do filósofo, em particular o copioso fundo atrelado ao Collège de France e parcialmente acessível ao público na sede normanda do Institut Mémoires de l'Édition

\footnotetext{
${ }^{1}$ BERT, Jean-François. Proximité, reserve et emprunt: la place de Michel Foucault dans la sociologie en France. Tese (Doutorado) — Université de Paris VIII, 2006.
}

Contemporaine (IMEC-Caen). Além de participar da catalogação de parte do acervo aí depositado, ele trouxe a público, como editor, materiais inéditos e/ou pouco conhecidos ${ }^{2}$. Trata-se, portanto, de alguém que domina como poucos o que resta da cozinha de um eminente pensador.

No que diz respeito ao recorte de conteúdo, o livro redigido por Bert tem por particularidade manter em segundo plano a relação de Foucault com a tradição francesa propriamente filosófica. Dado que seu "objeto" consagrou-se por propor pontes entre saberes, é legítimo, sustenta o autor, explorar sua produçáo a partir de outras perspectivas disciplinares. Trata-se, no caso, de abordar conceitos e procedimentos analíticos foucaultianos que reverberaram no campo das ciências sociais, discutindo igualmente as chaves com que isso foi feito.

Para tanto, Introduction à Michel Foucault oferece ao leitor, após uma breve introdução (p. 3-7), cinco capítulos, os quais possuem tamanhos e escopos diferentes. O primeiro deles, Itinéraire, mescla dados biográficos, contexto intelectual e

\footnotetext{
2 Penso, em especial, na edição em livro da emissão radiofônica que uniu Foucault e Raymond Aron logo após a publicação de As palavras e as coisas (Les mots et les choses). Cf. ARON, Raymond; FOUCAULT, Michel. Dialogues. Paris: Nouvelles Éditions Lignes, 2007. Jean-François Bert também edita, ao lado de Philippe Artières, o Portail Michel Foucault, um site obrigatório para os interessados na obra do filósofo francês (<http://portail-michel-foucault.org/>). Construído com o apoio da École des Hautes Études en Sciences Sociales e do Institut Mémoires de l'Édition Contemporaine, tal centro virtual, além de manter uma agenda atualizada dos eventos relacionados a Foucault, disponibiliza um número cada vez maior de documentos inéditos (correspondências, notas de curso, entre outros).
} 
a dinâmica das primeiras obras. Fica-se nele sabendo que Foucault, oriundo de uma família de médicos de província, dedicou-se inicialmente ao estudo da psicopatologia. A trajetória escolar e universitária privilegiada, marcada pela entrada na École Normale Supérieure e pelo sucesso no concurso de agrégation de philosophie, também é evocada. Pena, nesses dois casos, que Bert não tenha discutido com mais detalhes as implicaçóes desses estribos sociais, os quais estão longe de ser evidentes mesmo a um universitário francês. Por outro lado, as discussóes acerca da unidade/diversidade que caracteriza a obra de Foucault (p. 12-16) e sobre a influência do estruturalismo em sua formação (p. 16-21) são muito benfeitas. $O$ autor insere, ainda, algumas páginas interessantes sobre a militância foucaultiana no seio do Groupe d'Information sur les Prisons (GIP), a qual ajuda a entender melhor sua produção na primeira metade dos anos 1970 (p. 22-25).

A dinâmica do livro muda nos três capítulos seguintes. Bert isola então temas de interesse para os cientistas sociais na produção de Foucault, discutindo-os a partir de uma análise vertical de seus livros, cursos e artigos. A abordagem segue uma sequência cronológica, o que permite visualizar com maior clareza as transformaçóes e as continuidades das preocupaçóes do filósofo. Não se trata, porém, de um mero expediente de leitura interna: o autor tem o cuidado de problematizar igualmente a recepção crítica dessas obras e de estabelecer paralelos entre elas e trabalhos constituídos a partir de outros matizes analíticos.

Nessa direção, Réguler par la norme, o segundo capítulo, investe nas instituiçôes disciplinares. Bert discute aí as três grandes obras de Foucault dedicadas ao tema: Histoire de la folie (p. 28-36), La naissance de la clinique (p. 36-44) e Surveiller et punir (p. 44-56). Em todos esses casos, trata-se de compreender como um saber (a medicina ou o direito) se apodera e molda corpos a partir de instituiçôes específicas. As referidas obras não trabalham, porém, com a mesma ênfase. Segundo Bert, em Histoire de la folie e em La naissance de la clinique, discute-se um movimento de internamento de indivíduos, de sua separaçáo do mundo.
Em Surveiller et punir, por outro lado, o filósofo discutiria o processo de internalização da própria noção de doença ou crime, o qual, a partir do século XIX, impõe-se a todos os indivíduos, estando eles confinados ou não. O leitor também ganha ao ver os trabalhos de Foucault contrastados com os de Erving Goffman, Robert Castel e Luc Boltanski. Por fim, nota-se a existência de um bom apanhado, embora não exaustivo, de críticas aos referidos trabalhos (visita-se, entre outras, a acolhida positiva da Histoire de la folie pelo grupo dos Annales, ou então a crítica dirigida por psicólogos à mesma obra quanto ao estado lacunar das fontes e à romantização do medievo ocidental).

O terceiro capítulo, Vers une analythique des pouvoirs, concentra-se na reflexão foucaultiana acerca dos vínculos sociais. Atendo-se aos cursos proferidos no Collège de France na segunda metade da década de 1970 - Il faut défendre la société, Sécurité, territoire, population e La naissance de la biopolitique - , Bert mostra como, graças à noção de "genealogia", o filósofo se diferenciou das concepções de sociedade à época sustentadas por marxistas e estruturalistas. Com efeito, por meio da crítica à concepçáo hobbesiana de poder, a qual supóe um pacto e um lugar do poder, Foucault avançou na análise relacional dos mecanismos de dominação, entendendo a sociedade como um arquipélago de poderes que se interpenetram. Náo por acaso, o autor estabelece paralelos entre a produçáa foucaultiana e a de outros expoentes das ciências sociais: Norbert Elias (p. 62-64), Max Weber (p. 68) e mesmo Karl Marx (p. 71). E há mais: são também discutidas aqui as investigaçôes de Foucault sobre as formas de poder dominantes no Ocidente desde o Antigo Regime (a "soberania real", o "regime disciplinar" e a "era da biopolítica"), bem como se apresenta ao leitor o conceito de "governamentalidade", forjado em meio a essas investigações. $\mathrm{O}$ único senão maior quanto a essa parte do livro diz respeito à ausência de uma comparação com outros expoentes da universidade francesa que, percorrendo caminhos outros, pensaram as mesmas questôes. Vale dizer: a opção por reatualizar o método genealógico prescrito por Nietzsche não foi a única alternativa para a crí- 
tica de uma apreensão monolítica do poder e da sociedade. Entre tantos outros, Pierre Bourdieu e Maurice Godelier, operando dentro dos quadros das próprias tradições marxistas e estruturalistas, lograram realizar algo similar ${ }^{3}$.

Pratiques de soi et rapport à l'autre, o capítulo seguinte, encerra a discussão sobre a produção foucaultiana tratando de seus três trabalhos voltados à história da sexualidade, as últimas publicaçôes feitas enquanto Foucault vivia. Sobre o primeiro volume dessa série, Volonté de savoir, Bert chama a atençáo tanto para a continuidade em relação ao que já foi visto (a relação entre poder e saber, bem como o impacto e a interiorização dessa relação nos corpos) quanto para a inovação contida na proposta do filósofo (no caso da sexualidade, enfatizar não a repressão, mas a produção concomitante de diversas sexualidades que ora são encorajadas, ora marginalizadas) (p. 81-88). Já no que diz respeito às demais obras que compóem a série, Usage des plaisirs e Le souci de soi, a ênfase recai sobre a mudança de foco da análise foucaultiana. Com efeito, trata-se de problematizar agora o modo como um indivíduo governa sua própria sexualidade, reconhecendo-se como sujeito. Bert ainda discute as implicaçóes do recorte civilizacional proposto por Foucault (a história do Ocidente, a começar por Grécia e Roma antigas) (p. 88-96).

Fazendo as vezes de conclusão, Penser avec Foucault, o quinto capítulo, trata da recepção atualmente acordada ao filósofo entre cientistas sociais franceses. Para tanto, o autor sugere que tais apropriaçóes venham se dando em quatro direçôes. Em primeiro lugar, valoriza-se em Foucault uma história cuja verdade seja relativa e não global, sensível ao que se passa às margens da sociedade $\mathrm{e}$ à sua própria condição narrativa (p. 99-100). Em segundo lugar, pratica-se hoje, a partir da obra foucaultiana, certa análise do discurso que é, em verdade, uma investigação arqueológica sobre as condiçóes, os efeitos e os destinos dos enunciados (p. 100-102). Em terceiro lugar, tende-se a valori-

\footnotetext{
${ }^{3}$ Destaco aqui, em especial, as seguintes obras: BOURDIEU, Pierre. Esquisse d'une théorie de la pratique. Paris: Seuil, 2000 [1972]; e GODELIER, Maurice. O enigma do dom. Rio de Janeiro: Civilização Brasileira, 2001 [1997].
}

zar mais discussões acerca da relação entre saberes e poderes (p. 102-103). Por fim, um último legado de Foucault diz respeito à sua postura crítico-filosófica náo normativa, mais preocupada em provocar perplexidade e estranheza que em apontar caminhos a serem seguidos (p. 103-105). Essa parte do livro apresenta, no entanto, alguns problemas. Um deles é o silêncio ao qual são relegadas as apropriaçóes acima mencionadas. Bert náo identifica com precisão quem são os pesquisadores que se engajaram por tais vias e como o fizeram. Outro problema reside na própria construçáo do argumento, que tende a transformar tais apropriaçôes em "lições". Tratar-se-ia de uma concessão ao gênero manual? Ou seria simplesmente um efeito natural da rotinização do carisma de um autor, transformado em fonte de ensinamentos por seus intérpretes autorizados? A despeito das eventuais reservas, e por tudo o que foi dito ao longo desta resenha, o livro apresenta ao público não especializado um balanço equilibrado e sofisticado da produção de um autor que náo se pode hoje facilmente ignorar. As editoras brasileiras prestariam serviço à comunidade acadêmica se optassem por uma traduçãó ${ }^{4}$.

E quanto aos aspectos materiais e editoriais da obra? Voltada a um grande público e pensada como uma "síntese atualizada", a coleção Repères da editora La Découverte privilegia um formato de bolso, colando as páginas, compostas de uma variante de papel offset, na lombada. Ou seja, enquanto objetos, seus livros não são feitos para durar. Mas, se houve economia no quesito material, a edição merece elogios. Além de uma bibliografia bastante completa e atual, o livro de Bert apresenta, ao lado de um quadro de referências contendo publicaçóes, engajamentos e vínculos institucionais de Foucault em ordem cronológica (p. 117-120), um índice onomástico e temático (p. 121-122), algo extremamente útil ao leitor e cada vez mais raro.

\footnotetext{
${ }^{4}$ Fui informado pela editora La Découverte que os direitos da obra no Brasil foram adquiridos pela Parábola Editorial e que uma eventual tradução deve aparecer até inícios de 2013.
} 